\title{
2
}

\section{THE THINKING TOGETHER APPROACH TO DIALOGIC TEACHING}

\author{
Neil Phillipson and Rupert Wegerif
}

\section{Summary}

Dialogic teaching approaches involve teaching through dialogue and teaching for quality dialogue. Engaging in dialogue can promote deeper conceptual understanding as participants explore ideas from different perspectives in a caring, collaborative, critical, and creative manner. Reflective practice supported by "ground rules" that help to define and develop good quality dialogue enhances efficacy and promotes personal development. The Thinking Together approach, developed by Dawes, Mercer, and Wegerif in the 1990s, has been shown to be effective through evaluations in the UK, Mexico, South Africa, and China. We outline the main principles for teaching Thinking Together and summarize the research evidence.

\section{Introduction}

\section{What is dialogue?}

Thinking Together is one of a number of dialogic teaching strategies that have been shown to have a positive impact on learning and attainment in schools. One thing these approaches have in common is, perhaps unsurprisingly, that they encourage teaching through dialogue. They also involve teaching students how to get better at dialogue - teaching for dialogue. It seems to follow that any success with the application of dialogic approaches in the classroom will probably need to be founded on an understanding of the nature of dialogue.

The word dialogue does not, as some people seem to think, refer only to an interaction between two people. The Greek roots of the term are dia, which can be translated as "through" or "across," and logos, which is a resonant term often translated as "discourse," "speech" or "reason." We might then ask, what 
is it that people are speaking or reasoning across or through? One answer to this question is that they are reasoning across the difference between perspectives, often the difference between their personal and most immediate perspective and another perspective experienced as being other to them or outside them (whether it be the perspective of one or more other people with whom they are speaking, or the perspective of the author of a text they are reading, or a perspective that has been at the back of their mind since they heard it or read it some time ago).

The important point here is that to engage in dialogue is to acknowledge and respond to other perspectives; to seek to understand them, to be sensitive to the differences between them and one's own understandings; and to use these differences as a resource to generate new perspectives and to achieve richer understandings of ideas and of other people. To enter into dialogue is not to endeavor to impose one's own view or to uncritically accept the view of a more authoritative other, but rather to engage in a shared search for understanding and meaning; it is to enter into a relationship based on mutual respect. Indeed, engaging in a dialogue could be defined as an act of 'thinking together,' the name of the approach to dialogic teaching explored in this chapter.

A great deal of theory surrounds the nature of dialogue, and some understanding of the central ideas can deepen teachers' thinking about the subject and indeed influence their practice. A thorough introduction to this theory is beyond the scope of the present chapter; Wegerif (2019) offers a useful review of the literature.

The Jewish thinker Martin Buber encourages us to think about dialogue in terms of the way in which we relate to others. He distinguishes between what he calls just experiencing others and entering into relation with them. When we experience others we see them as objects external to ourselves; we seek to learn about them, but always from our own external perspective: "The man who experiences has no part in the world. For it is 'in him' and not between him and the world that the experience arises. [The world] does nothing to the experience, and the experience does nothing to it." (Buber, 1958, p. 13). Buber referred to this as an "I-It" attitude which, although necessary for day-to-day life, does not allow one to enter into genuine dialogue but rather to engage in instrumental transactions. In the "I-Thou" attitude, by contrast, we encounter the other as a whole being; rather than gaining experience of each other in our individual minds, we encounter each other in a space that Buber referred to as the "in-between" - our minds enter into relation with each other. "Relation is mutual. My thou affects me as I affect it." (Buber, 1958, p. 20). For Buber, entering into dialogue involves entering into an "I-Thou" relationship with the other.

Mikhail Bakhtin, the Russian philosopher and literary theorist, provides us with a commonly referenced definition of dialogue as interaction in which every answer gives rise to another question; this leads us to think of dialogue as an unending process or quest for truth, not a short exchange in which "correct" answers are accepted uncritically (Bakhtin, 1986, p. 168). Bakhtin also makes an important distinction between the "authoritative word" and the 
"persuasive word." The authoritative word instructs or transmits but does not call us into dialogue. Consider a sign that reads "No smoking": we can accept or reject the instruction, but we are not invited to seek further understanding of it. The persuasive word in contrast is framed with us in mind - it might take on our own vocabulary or concerns, for example. It "enters into us" and stimulates our own answering words, calling us to think and make meaning. Bakhtin might argue that the dialogic persuasive voice is essential for deeper learning because to truly understand something we need to be able to express it ourselves with our own words.

So, from a more practical point of view, how might we recognize exchanges in the classroom that are more "dialogic?" Robin Alexander (2017a), whose work on dialogic teaching has been central to its development in the UK, offers a set of principles which might usefully guide us. He states that dialogic teaching should be:

- Collective (the classroom is a site of joint learning and enquiry);

- Reciprocal (participants listen to each other, share ideas and consider alternative viewpoints);

- Supportive (participants feel able to express ideas freely, without risk of embarrassment over "wrong" answers, and they help each other to reach common understandings);

- Cumulative (participants build on their own and each other's contributions and chain them into coherent lines of thinking and understanding);

- Purposeful (classroom talk, though open and dialogic, is structured with specific learning goals in view).

The bolded text provides us with some useful indicators of what classroom dialogue might involve. The section on "ground rules" later in this chapter is also concerned with developing a shared understanding of what dialogue might "look like" in the classroom.

\section{Why is dialogue educationally valuable?}

Much of schooling is concerned with helping students see the world in new ways by introducing them to disciplines such as mathematics, science, and history. This means introducing them to ideas that are removed from everyday experience, sometimes by providing them with new language and new concepts with which to think, and sometimes by bringing new meaning to existing concepts. For example, students will have plenty of everyday experience of the concept of love, but will probably not be familiar with the way that the term is used in Christian theology or in other faith traditions.

The Russian psychologist Lev Vygotsky referred to the kind of concepts encountered in academic disciplines as "scientific concepts" and suggested that they are 
formed through systematic instruction which introduces them in relation to a range of other concepts. "Everyday concepts," in contrast, are learned in a more unconscious, less systematic way through interactions with the world in the course of normal living. The set of everyday concepts that a person acquires will depend on their experiences, and everybody's experiences are unique (Wells, 1999).

This presents a challenge to the teacher trying to introduce a student to scientific concepts. We make meaning of all new ideas by relating them to our existing understandings of the world, including our everyday concepts. If we all have a unique set of everyday concepts, it seems inevitable that we will come to understand new ideas in different ways. This means that teaching about scientific concepts requires more than the transmission of linguistic definitions from teacher to student. The student is actively involved in constructing his or her own knowledge, and the knowledge constructed by different students is different.

Vygotsky believed that the development of higher mental functions, including the development of conceptual understanding, is a social process:

Any function in the child's cultural development appears twice or on two planes. First it appears on the social plane and then on the psychological plane. First it appears between people as an inter-psychological category, and then within the child as an intra-psychological category. Social relations... genetically underlie all higher functions and their relationships. (Vygotsky, 2012, p. 163)

Dialogue (between teacher and student or between students) provides the social plane on which conceptual understanding can be developed. It offers students the opportunity to construct and reconstruct knowledge through a shared process of questioning, answering, explaining, exemplifying, comparing, connecting, applying, evaluating, and so on. It enables students to become sensitive to the differences between their understandings and those of their peers or teachers and to use these differences to stimulate further meaning making. Ultimately, coming to understand a discipline or school subject involves making a switch from one's own everyday perspective to the perspective of the discipline; the ability to switch perspectives in this way is precisely what is learned in dialogues.

Two more points should briefly be made about the educational value of dialogue, although a deep exploration of them is beyond the scope of this chapter. First, there is growing evidence that dialogic education is an effective way to teach general and transferable thinking skills and dispositions (Sutherland, 2006; Wegerif, 2018). This is based on the view that thinking can be described as an attribute of dialogue. In dialogues we learn to engage with other points of view in caring, collaborative, creative, and critical ways. These dispositions can be internalized; they can become part of the way we think and can complement rigorous disciplinary knowledge.

Second, and perhaps most important of all, there is a moral obligation to teach dialogue. The philosopher Dmitri Nikulin (2010) tells us, "Dialogue is a therapy 
- perhaps the therapy - against the misrecognition of one person by another." In a world in which so much suffering is caused by the failure of one person to recognize the humanity of another, we would argue that not teaching dialogue is an abdication of our moral responsibility as educators.

\section{To what extent do we find dialogue in the classroom?}

The brief descriptions of dialogue given above might be sufficient to make us question how much of the oral interaction seen in classrooms is dialogic. Observational studies have tended to "not much" (Littleton \& Mercer, 2013).

Most teachers will be able to identify with research suggesting that a routine known as Initiation-Response-Evaluation (IRE) is ubiquitous in schools (see Vrikki et al., 2019, and references therein). In this model of interaction teachers initiate discourse with questions that are often intended to check recall and require only brief responses from students; they then evaluate these responses with regard to their "correctness" (Sinclair \& Coulthard, 1975). The aim of such exchanges seems to be to ensure that correct answers have been memorized and can be recalled; students are being encouraged to uncritically accept the authoritative word rather than being called to think and make meaning on the social plane by the persuasive word, and teachers are only engaging with students' perspectives in a limited manner - the relationship is very much one of "I-It."

Other studies have found that students are much more likely to be involved in "disputational talk" (characterized by individuals trying to impose their views on others in an egocentric way) or "cumulative talk" (characterized by individuals uncritically agreeing with each other in order to maintain group harmony) than they are in productive dialogue (Wegerif \& Scrimshaw, 1998).

Perhaps it should be stressed at this point that forms of classroom talk other than dialogue are useful. Robin John Alexander (2017b) is keen to point out the value of the teacher using a repertoire of talk types (which includes exposition, recitation, and rote). And Mortimer and Scott (2003) suggest that teachers need to match their "communicative approach" to their teaching purpose; there are times when an authoritative approach (including the use of IRE) is needed.

However, if we are to support students in bridging the gap between their everyday perspectives and the perspectives of their teachers and ultimately of the disciplines they are being introduced to, then we need to create more opportunities to engage them in dialogue.

So far, we have introduced the idea that teaching for dialogue should have a central role in teaching for deeper understanding and for general intellectual as well as ethical dispositions and competencies. The next section provides a description of one dialogic approach that has had a proven impact in developing conceptual understanding and thinking skills in the classroom: Thinking Together. 


\section{The Thinking Together approach Overview}

The Thinking Together approach was originally developed by Lyn Dawes, Neil Mercer, and Rupert Wegerif in the 1990s (Dawes, Mercer \& Wegerif, 2000). The approach offers a way of teaching through and for dialogue that fits easily into the teaching of subjects within a normal school curriculum, offering an alternative to potentially more time-consuming approaches such as Philosophy for Children. The teacher develops the capacity for dialogue in the classroom by working with students to establish shared "ground rules for talk." The co-construction of an accessible set of ground rules involves the children in the process of improving the quality of dialogue, creating better opportunities for reflection and metacognition than those created by some dialogic teaching approaches, and perhaps increasing the likelihood of students recognizing and moving away from unproductive and often implicit social norms. The ground rules are applied to create an environment in which "Exploratory Talk" can flourish, both in whole-group activities and in small-group activities (the latter being the main focus of the original approach). Exploratory Talk is dialogic talk with a focus on shared inquiry, asking questions, explaining, exploring alternatives, and generally seeking to understand the other participants' perspectives and the topic at hand.

The use of ground rules to support the development of classroom dialogue was a response to research (discussed above) suggesting that talk that might be described as dialogic occurs relatively rarely in schools and that classroom talk is more likely to be "disputational" or "cumulative," rendering much classroom talk unproductive (Wegerif \& Scrimshaw, 1998). It could be argued that the implicit ground rules students bring with them to the classroom are responsible for these types of talk. If a student has an implicit belief (or ground rule) such as "You have to win an argument to be strong," then they are likely to become involved in disputational talk. An implicit belief such as "Argument is a bad thing" might give rise to cumulative talk. Through shared reflection on classroom talk, these ground rules can be made explicit and alternatives can be proposed which might become a shared resource with which students and teachers can create an environment for dialogue. If students internalize these ground rules for talk, then they will be more likely to use dialogic talk in contexts beyond the classroom; the way they "think together" with others may be fundamentally changed (as indeed may their habits of thinking as an individual).

\section{The use of ground rules}

A teacher looking to use the Thinking Together approach in the classroom might begin by explicitly teaching children about the value of talk for communicating and learning together. It might be acknowledged that there are different "kinds" of talk (including cumulative and disputational) that may be useful in different situations, and that not all classroom talk is productive. Students can 
be encouraged to reflect on the quality of talk that is productive - when they are trying to solve problems together, for example. The way language can be used as a tool for Thinking Together might be explored: the value of terms like "I think...," "because...," and "why...?" for sharing and justifying thinking and reasoning together can be discussed. In this way, we begin to give the students the tools they will need to develop "higher mental functions" and co-construct meaning on the social plane. Students can then consider together what "ground rules" might guide them to produce the desired quality of talk.

The authors of Thinking Together intended that the ground rules used would emerge from students' developing awareness of what worked and what did not work for them; ground rules would be somewhat different in each context and would evolve during a period of reflective practice. Nevertheless, some common features that might be expected include commitments to:

- $\quad$ Sharing relevant knowledge;

- Listening to everyone's ideas attentively and treating them respectfully;

- Accepting that claims should be challenged and that the reasons underpinning claims and challenges should be shared and explored;

- Actively seeking and considering alternatives before any decisions are taken;

- Taking shared responsibility for decisions;

- Reaching agreement whenever possible.

The need to encourage students to reach agreement could be questioned in the light of the foregoing discussion about the nature of dialogue, but Littleton and Mercer (2013), citing evidence from a number of authors, suggest that the effort to reach consensus (perhaps more importantly than the realization of this goal) encourages students to engage more deeply with the views of others and to give more consideration to their own ideas and the reasons underpinning them.

A practical guide for teachers introducing Thinking Together into the classroom has been provided by Dawes et al. (2000) and includes lesson plans for developing and applying a set of ground rules. Materials and references are available on the website https://thinkingtogether.educ.cam.ac.uk.

\section{An alternative approach to Thinking Together ground rules}

In our 2017 book Dialogic Education: Mastering core concepts through thinking together, we suggest that the Thinking Together approach might be enhanced by the application of the "4Cs Framework" used to develop the quality of dialogue in Philosophy for Children (P4C) (Phillipson \& Wegerif, 2017).

The American educator Matthew Lipman developed P4C in the 1960s and '70s; he considered good thinking (which might include good Thinking Together, or dialogue) to be multidimensional (Lipman, 2003). His three proposed modes of thinking - critical, caring, and creative - were later augmented with a fourth 


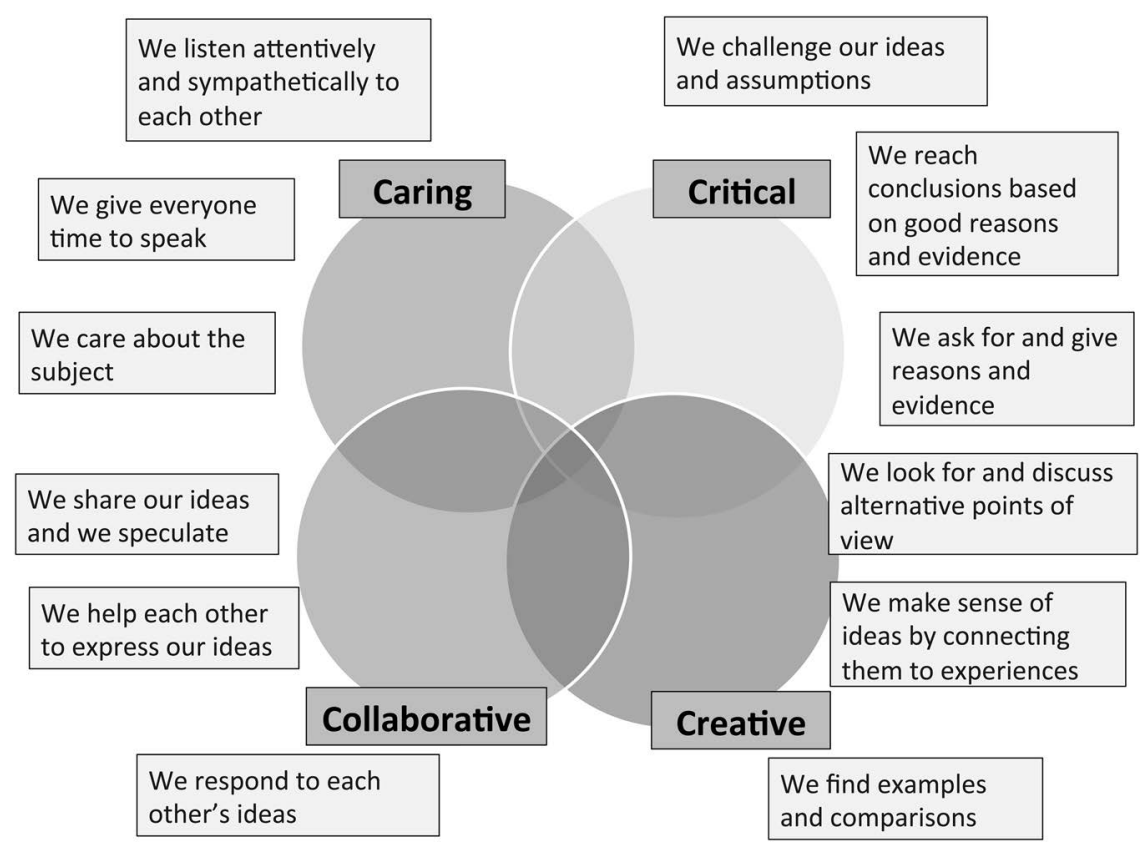

FIGURE 2.1 Ground rules for critical, caring, collaborative, and creative thinking.

mode - collaborative - by UK educator Roger Sutcliffe. The four modes of thought are very much interrelated.

The 4Cs can be defined to some extent through the development of related "ground rules" as illustrated in Figure 2.1.

While such ground rules certainly do not provide a comprehensive delineation of the 4Cs and will need to be reviewed and developed over time, they provide an overview of what good Thinking Together entails and can be used to support students on their journey toward it.

These ground rules are a template to guide teachers. They are not simply imposed. Each class is asked to suggest ground rules after an experience of group work. Teacher reformulations of suggested rules in discussion with the class lead to the generation of a class set of ground rules for talk in the students' own words and do so in a way that students can feel ownership over them. These ground rules can then be revisited and developed as awareness of talk and sophistication in dialogue increases.

\section{The importance of reflection}

Whatever ground rules are established, deliberate and reflective practice is essential if they are to have the desired impact on the quality of talk. The value of metacognition and self-regulation to effective learning has become wellrecognized (you can find a useful summary of the evidence at https://educationendowmentfoundation.org.uk/evidence-summaries/teaching-learning-toolkit). 
Metacognition involves developing a conscious awareness of the strategies used to tackle a problem, as well as developing the capacity to evaluate the effectiveness of those strategies and adapt them accordingly. Ground rules represent an explicit statement of the strategies used to make Thinking Together effective. Teachers can guide students to identify when specific ground rules are being followed and to reflect on the impact they have on the dialogue and on progress toward tackling the problem at hand. Littleton and Mercer (2013) follow Vygotsky in suggesting that the responsibility for regulating Exploratory Talk passes from the teacher (external regulation) to the group (co-regulation) and to the individual student (self-regulation).

Reflection on the ground rules and their application may prompt some revision of the rules, and it also will allow the group to identify the skills and dispositions they need to focus on. These skills can be made the focus of subsequent sessions; lesson objectives may refer to both subject knowledge and the quality of talk. The value of skills such as "finding real examples to make your idea clearer" can be openly discussed, and the skill itself (including the features of language that might be indicative of its use) can be modelled. In addition to reviewing learning content at the end of a session, the progress made with the focus skills and dispositions can also be reviewed and fresh targets can be set.

If groups feel they are having difficulty enacting certain ground rules, then devices can be put in place to support them. For example, if members of a group feel that they are finding it difficult to give sufficient time for people to articulate complex ideas before being interrupted, then it might be suggested that an object is introduced, to be held by the speaker; speakers are not finished until they choose to pass the object to a person from whom they would like a response. If a group finds that some voices are becoming dominant and others are being excluded, the number of contributions that any one speaker can make might be limited (by issuing counters to be relinquished each time a contribution is made, e.g.). Once the device is deemed to have served its purpose it can be removed, and another skill can be focused on.

The use of ground rules to develop metacognition and self-regulation and to support groups to identify "next steps" in their development of dialogic talk is important. It allows groups to make progress with the quality of their dialogue and avoid "plateauing" at a relatively superficial level where ideas are politely exchanged but no real "thinking together" is done. This is the deliberate "teaching for dialogue" that characterizes all successful dialogic teaching approaches.

\section{Lesson structure/grouping}

The way the Thinking Together approach is used is, of course, flexible and will be informed by the teacher's professional judgment. Both whole-group and smallgroup activities are likely to be used, and the first thing to consider might be the classroom layout. 
For whole-group sessions, a circle or horseshoe layout (with or without desks) can have real advantages because it allows all participants to see each other and so facilitates deeper listening and responding. It also allows the teacher to take a position within the circle; this might signal that in this particular mode the teacher is not seeking to introduce authoritative knowledge but rather to facilitate students' thinking about the knowledge they have already engaged with (in the language of Mortimer and Scott (2003), we might say that the teacher is signaling a conscious decision to change the communicative approach to one that is both interactive and dialogic). Even in small-group sessions of three or more a circular (or, in the case of threes, triangular) seating arrangement will be useful.

A typical Thinking Together session might involve three main sections. In the first section, the teacher might introduce the session's purpose to the whole class. Relevant prior learning might be reviewed, and the objective of the current session, in terms of the subject knowledge being developed, might be explored. A learning objective relating to the quality of the students' talk may then be identified (it may indeed have been identified following a review of the previous session), possibly with reference to the class's ground rules. The skills and language involved in meeting this objective can be discussed and modelled; the group might play a short game to focus themselves on the skills being developed (e.g., a game involving listening, responding, or reasoning).

In the second section, the class might be given the opportunity to engage in small-group dialogue around a question or problem. The composition of these groups is worthy of consideration. Groups of three work well because they introduce a plurality of perspectives without allowing too many voices to be heard. Other factors to consider include gender and level of prior attainment; the task's literacy demands might also be taken into account.

In the final section, the whole group might come back together to share ideas and questions emerging from the group work. During this session, the teacher might focus on the need to ensure that any differences between the students' ideas and the "correct" ideas the teacher wishes the children to learn are noted and addressed. It is important that this doesn't become a session in which misconceptions are shared and exacerbated, but is rather one in which the students and the teacher work together to reveal flaws and inconsistencies in reasoning and discrepancies between the students' understandings and the accepted view. This can be seen as an important point in bridging the gap between everyday concepts and scientific concepts, as discussed in the introduction. In sum, assessment is an important part of the process; dialogue is a useful way of making students' learning "visible," and joining the dialogue enables the teacher to respond effectively to his or her students.

\section{Facilitation of dialogue}

There is more to the facilitation of dialogue than might be anticipated. We have already pointed out the important differences between talk that might be 
described as dialogic and the Initiation-Response-Evaluation-style exchanges seen in many classrooms. Perhaps the first decision to be made by the teacherfacilitator is whether to be present at all. In the presence of the teacher, students can be less willing to engage in active meaning-making (often characterized by a willingness to make tentative suggestions and hypotheses) and more likely to present closed assertions that can be judged by the teacher (Barnes, 1976). This could be used to justify the decision to allow students the opportunity to work with small groups of peers in the absence of the teacher; it seems likely that students will be more actively involved in making meaning of their learning.

When teachers decide to join the dialogue, they need to be conscious of the potential impact of their presence; it might be useful to be explicit with the students that in this session the "rules of the game" are changed and that the teacher is interested in the students' ideas and understandings. In a sense, teachers are positioning themselves as part of a process of enquiry and as learners. For a good portion of the time the teachers might choose to be absent in the sense that he or she does not seek to influence the content of the dialogue. Instead, any questioning might be designed to encourage students to elaborate and to respond to each other's ideas. Here the 4Cs framework suggested above can be a useful guide - how can the facilitator encourage caring, collaborative, critical, and creative thinking without inhibiting the students' sharing of ideas? At this stage, a Socratic questioning style is often useful; examples of Socratic questions include: "Can you tell us more about that?," "What are the reasons/what is the evidence supporting that?," "Can you give an example of that?," "Would somebody like to respond to that?," "Are the points made by $X$ and $Y$ the same or are they different?," "Is there an alternative point of view?," "Can we think of an example where that wouldn't work?," "Who can summarize what's been said - have we reached any conclusions?" Such questions will support students to think harder and to engage in a richer dialogue without influencing their thinking.

The teacher/facilitator may also use questioning to support students to make meaning by connecting abstract ideas to lived experiences. For example, if students are grappling with an abstract idea such as "force," asking for examples of forces experienced in the classroom and in everyday life may be useful. In this way, students can use examples to identify common features of forces and construct a provisional definition of force, and they can check the validity of that definition by applying it to various real examples (the facilitator of dialogue is building bridges between everyday experiences and disciplinary knowledge, and between Vygotsky's everyday concepts and scientific concepts). In one such discussion in the first author's classroom, the suggestion that a force "makes things move" was challenged through reflection on the students' experiments with and everyday experiences of air resistance and friction, leading them to adopt the idea that a force "changes the way things move." It is certainly worth noting here that the success of this strategy is predicated on the students having rich experiences on which to reflect. 
In all of this, the teacher as facilitator is seeking to deepen the collective thinking of the group and at the same time is modelling the use of questioning to deepen thinking and open up dialogue. At some point, however, the teacher's view of the knowledge in question needs to re-enter the dialogue.

One of the principles of the successful dialogic teaching approach "Accountable Talk" is accountability to knowledge (Resnick \& Schantz, 2015). In their explanation of this idea, Michaels, O'Connor, and Resnick (2007, p. 289) state that, "A knowledgeable and skilled teacher is required to provide authoritative knowledge when necessary and to guide conversation toward academically correct concepts" (they also stress the synergistic relationship between the effective acquisition of knowledge and good discourse). Alexander (2017a, p. 6) also acknowledges the tension between a "Bakhtinian commitment to dialogue as unending" and the need to pass on accurate knowledge as it is currently understood. This might involve the teacher asking substantive questions that reveal the inadequacies of some of the ideas that have been offered and the superiority of other ideas. The first author, Neil Phillipson, facilitated one discussion in which 9-year-old pupils were divided as to whether lava cooling and forming rock was an example of freezing, the main objection being that freezing happened "at or below $0^{\circ} \mathrm{C}$." The facilitator asked questions such as "Do you think the liquid gold we saw earlier freezes at or below $0^{\circ} \mathrm{C}$ ?," "Does chocolate need to be below $0^{\circ} \mathrm{C}$ before it becomes a solid?," and "Is water the only substance that freezes?" to challenge the misconception that had emerged. Teachers will find it useful to consider likely misconceptions such as the one described above and to plan their substantive questions in advance of the session.

The teacher may decide at the end of a dialogue to return to an exposition of the accepted version of the knowledge under discussion, perhaps stepping out of the circle to indicate the change of "mode" of teaching or communicative approach. In this case, it may still be useful to respond to the ideas shared by the students rather than giving an authoritative explanation that makes no reference to their ideas and perhaps thereby devalues them and disenfranchises them from the process of active meaning making. The talk would become less interactive, but it would remain dialogic in the sense that the students' views are represented and valued by the teacher.

Some argue that as soon as a predetermined endpoint is introduced, the talk ceases to be recognizably dialogic. One response to this might be to return to the "bigger picture" of education as dialogue. The teacher might openly acknowledge that any conclusions reached in the discussion are provisional and will develop as the students' experience (and indeed the experience of the relevant discipline and of humanity) grows. This might encourage students to maintain a curious and questioning disposition toward the subject and to remain open to fresh perspectives. As long as the overall endpoint of the education remains the achievement of fuller participation in dialogue - the dialogue of scientific enquiry, for example - then this process of guided scaffolding can be understood as part of dialogic education. 


\section{Evidence for the effectiveness of Thinking Together}

There have been several experimental implementations and evaluations of the Thinking Together approach in the UK and other countries, including Mexico and South Africa. These evaluations show that significant improvements can be achieved in curriculum areas and also in reasoning test results. When Thinking Together was applied to science teaching for 1 year in upper primary to about 200 students, it produced statistically significant gains in relation to a control group on both a standardized science knowledge test and a standardized nonverbal reasoning test (Mercer, Dawes, Wegerif, \& Sams, 2004). A separate intervention study at upper primary level with 64 students (ages 9 and 10), compared the effects of teaching Thinking Together in an experimental class with the same measurements in a matched control group. The study, which lasted over three months with a single, 1-hour Thinking Together lesson taught each week, led to average increases of $10 \%$ in scores on nonverbal reasoning both for groups and for individuals (Wegerif, Mercer, \& Dawes, 1999). Similar results were reproduced in Mexico (Wegerif, Linares, Rojas-Drummond, Mercer, \& Velez, 2005), South Africa (Webb, Whitlow, \& Venter, 2017), and Belgium (T'Sas, 2018). The recent study in Belgium was particularly interesting because it was an accurate reproduction study of the original work in the UK. It achieved very similar results, suggesting that the positive impact of Thinking Together on reasoning and also on learning in science is a robust finding. As with most classroom-based intervention research, criticisms could be raised about the rigour of each of these studies. The extra attention paid to students in the target condition might have led to a Hawthorne effect, which is a positive increase in motivation due to the interest of teachers and researchers. Some critics have suggested that the increased scores in nonverbal reasoning for individuals might have been influenced by group nonverbal reasoning tests done before the individual tests.

However, this quantitative evidence has been matched with qualitative research exploring how and why groups learn to think better together through engaging in Exploratory Talk promoted by the Thinking Together approach. Often this evidence is stronger than any statistical evidence because it is sometimes possible to show clearly how groups solve problems by talking together using the ground rules of Thinking Together that they could not solve before the intervention (Wegerif et al., 1999).

\section{Why does Thinking Together work?}

It appears that Thinking Together and other dialogic teaching approaches have an effect not only on the quality of classroom dialogue and groups' ability to effectively think together but also on the quality of individual thinking as measured by tests and achievement in specific curriculum areas. Thus we need to think about the mechanism of these impacts. 
Mercer (2016) offers three explanations. The first of these is that, when engaged in Exploratory Talk (dialogic talk as defined above), students can appropriate and apply the problem-solving strategies articulated by others; strategies are transmitted from one person to another through the use of language as a tool for thinking together. The second explanation relies on the idea that Exploratory Talk enables students to pool alternative strategies for solving a problem (or perhaps alternative perspectives on a concept), and hold them in creative tension together and co-construct new and better approaches (or understandings) which individuals learn and apply to other problems. Mercer points out that this explanation "locates the genesis of effective cognitive strategies in collective reasoning," thus linking individual learning and development to social activity and Thinking Together in accordance with Vygotsky's theory.

Mercer's third explanation points at the transformation of the individual through engagement in dialogic talk. Reflection on the quality of such talk, perhaps with reference to ground rules such as those discussed earlier in this chapter, allows a student to develop a metacognitive awareness of the effective strategies being used. Having experienced the value of searching for examples and counter-examples, searching for other points of view and so on in a dialogue, the student ultimately develops the disposition to do these things individually: their intramental thinking is transformed through intermental activity. The culturally based, social use of language leads to psychological development, again in accord with Vygotsky's ideas (Mercer, 2016).

It may also be that students become more comfortable with inhabiting a space in which multiple possibilities are held in tension together until a creative solution emerges (Wegerif, 2012). It may be that they begin to identify less with themselves and the need for their view to be validated (a disposition that leads one to become involved in disputational talk as described previously) and less with the group and their perceived position within it (a sense of identity that might lead one into cumulative talk) and more with the open-ended process of dialogue itself.

Developing students' ability to switch perspectives during dialogue may be fundamental to the impact of dialogic approaches. It is tempting to think that if a group of students have all sat through the same lecture - about justice, for example - then they will all have acquired the same "objective" understanding of the concept. But, as discussed earlier in the chapter, the sense we make of new ideas is dependent on our previous experiences. To make meaning of another's understanding of a concept like justice - to inhabit that perspective for a time without losing sight of our own perspective - is an effortful process and one that requires practice.

Perhaps it is this ability to genuinely inhabit other perspectives and encounter others in an "I-Thou relationship" that makes the words of others harder to dismiss and enables them to "enter into us" - to call us to think and make new meaning - in order for us to learn more deeply (see our earlier discussion of Buber and Bakhtin). 


\section{Conclusion}

In this article, we have presented a case for the centrality of dialogue in education for deeper understanding. To that end, we have illustrated this case with one approach to dialogic education, which is education that teaches an improved quality of dialogue. There is good research evidence that this approach, Thinking Together, not only improves thinking in groups but also thinking for individuals. It does this through addressing communicative competence and promoting dialogic dispositions, including dispositions such as listening carefully so as to be able to understand the perspectives of others.

\section{References}

Alexander, R. (2017a). Developing dialogue: Process, trial, outcomes. Paper presented as part of the symposium on professional development in dialogic teaching: Commonalities and constraints, 17th Biennial EARLI conference,Tampere, Finland. Retrieved from http://www. robinalexander.org.uk/wp-content/uploads/2017/08/EARLI-2017-paper-170825.pdf

Alexander, R. J. (2017b). Towards dialogic teaching: Rethinking classroom talk (5th ed.). Osgoodby, Yorkshire: Dialogos UK Ltd.

Bakhtin, M. M. (1986). Speech genres and other late essays. Austin, TX: University of Texas Press.

Barnes, D. (1976). From communication to curriculum. London, England: Penguin.

Buber, M. (1958). I and Thou [R. G. Smith, Trans.]. Edinburgh, Scotland: T \& T Clark. (Original work published 1923).

Dawes, L., Mercer, N. \& Wegerif, R. (2000). Thinking Together: A programme of activities for developing speaking, listening and thinking skills in children aged 8-11. Birmingham, England: Imaginative Minds.

Lipman, M., (2003). Thinking in education (2nd ed.). Cambridge, UK: Cambridge University Press.

Littleton, K. \& Mercer, M., (2013). Interthinking: Putting talk to work.Abingdon and New York: Routledge.

Mercer, N. (2016). Education and the social brain: Linking language, thinking, teaching and learning. Éducation \& Didactique, 10(2), 9-23.

Mercer, N., Dawes, L., Wegerif, R., \& Sams, C. (2004). Reasoning as a scientist:Ways of helping children to use language to learn science. British Educational Research Journal, 30(3), 359-377.

Michaels, S., O'Connor, C. \& Resnick, L. B. (2007) Deliberative discourse idealized and realized: Accountable talk in the classroom and civic life. Studies in Philosophy and Education, 27(4), 283-297.

Mortimer, E., \& Scott, P. (2003). Meaning making in secondary science classrooms. Berkshire, UK: McGraw-Hill Education.

Nikulin, D. (2010). Dialectic and dialogue. Stanford, CA: Stanford University Press.

Phillipson, N. \& Wegerif, R. (2016). Dialogic education: Mastering core concepts through thinking together. Abingdon and New York: Routledge.

Resnick, L. B., \& Schantz, F. (2015). Talking to learn: The promise and challenge of dialogic teaching. In L. B. Resnick, C. S. C. Asterhan, \& S. N. Clarke (Eds.), Socializing intelligence through academic talk and dialogue (pp. 441-450). Washington, DC: American Educational Research Association. 
Sinclair, J. M., \& Coulthard, M. (1975). Towards an analysis of discourse: The English used by teachers and pupils. Oxford, UK: Oxford University Press.

Sutherland, J. (2006). Promoting group talk and higher-order thinking in pupils by 'coaching' secondary English trainee teachers. Literacy, 40(2), 106-114.

T'Sas, J. (2018). Learning outcomes of exploratory talk in collaborative activities (Unpublished doctoral thesis). University of Antwerp, Belgium.

Vrikki, M., Kershner, R., Calcagni, E., Hennessy, S., Lee, L., Hernández, F., ... Ahmed, F. (2019). The teacher scheme for educational dialogue analysis (T-SEDA): Developing a research-based observation tool for supporting teacher inquiry into pupils' participation in classroom dialogue. International Journal of Research $\mathcal{E}$ Method in Education, 42(2), 185-203.

Vygotsky, L. S. (2012). The collected works of L .S. Vygotsky: Scientific legacy. New York: Springer Science \& Business Media.

Webb, P., Whitlow, J. W., \& Venter, D. (2017). From exploratory talk to abstract reasoning: A case for far transfer? Educational Psychology Review, 29(3), 565-581.

Wegerif, R. (2012). Learning to think as becoming dialogue: An ontologic-dialogic account of learning and teaching thinking in primary classrooms. In B. Ligorio \& M. Cesar (Eds.), Interplays between dialogical learning and dialogical self (pp. 27-45). Charlotte, NC: IAP Information Age Publishing.

Wegerif, R. (2018) A dialogic theory of teaching thinking. In L. Kerslake \& R. Wegerif (Eds.), Theory of Teaching Thinking: International perspectives (pp. 89-105). Oxon and New York: Routledge.

Wegerif, R. (2019) Dialogic education. Oxford research encyclopedia of education. Oxford, UK: Oxford University Press.

Wegerif, R., \& Scrimshaw, P. (Eds.). (1998). Computers and talk in the primary classroom. Bristol: Multilingual Matters.

Wegerif, R., Linares, J. P., Rojas-Drummond, S., Mercer, N., \& Velez, M. (2005). Thinking together in the UK and Mexico:Transfer of an educational innovation. Journal of Classroom Interaction, 40(1) 40-48.

Wegerif, R., Mercer, N., \& Dawes, L. (1999). From social interaction to individual reasoning: An empirical investigation of a possible socio-cultural model of cognitive development. Learning and Instruction, 9(6), 493-516.

Wegerif, R., \& Scrimshaw, P. (Eds.). (1998). Computers and talk in the primary classroom. Bristol: Multilingual Matters.

Wells, G. (1999). Dialogic inquiry:Towards a sociocultural practice and theory of education. Cambridge and New York: Cambridge University Press. 